\title{
Antología de
}

poesía cubana

orientalista. Idalia

Morejón Arnaiz y

Pacelli Dias Alves

de Souza (Org).

Sáo Paulo: Malha

Cartonera, 2018,

$88 \mathrm{p}$.

Yoandy Cabrera Ortega

Recebido em: 23 de março de 2019

Aceito em: 13 de julho de 2019

Filología Clásica por la Universidad Complutense de Madrid. Es profesor de Hispánicas y Clásicas en Rockford University. Además, es autor de Adán en el estanque (poesía, 2013) y coautor de Ballet clásico y tradición grecolatina en Cuba (ensayo, 2019).

Contato:yoandyc@gmail.com Estados Unidos 
El volumen, Antología de poesía cubana orientalista, con selección de Idalia Morejón Arnaiz y Pacelli Dias Alves de Sousa ha sido publicado por la editorial Malha Fina Cartonera en 2018 y es el primero de su tipo que recoge los diversos modos en que la poesía cubana ha representado lo oriental desde el siglo XIX hasta el presente, a lo largo de más de cien años. Son dieciocho autores antologados, en una muestra que va desde José Martí, nacido en 1853, hasta Carlos Alberto Aguilera, nacido en 1970. Al mismo tiempo, recoge autores que viven tanto dentro como fuera de la isla. Lo primero que llama la atención al repasar el índice de la antología es que muchos de los mejores poetas de la tradición cubana de todos los tiempos (como Martí, Julián del Casal, José Lezama Lima, Virgilio Piñera, Néstor Díaz de Villegas y Juan Carlos Flores) han intentado abordar lo oriental en algún momento de sus obras líricas. Se trata, además, de una edición bilingüe español/portugués que cuenta con más de una decena de traductores entre los que se encuentran los antologadores.

Pacelli Dias Alves de Sousa firma las palabras del prólogo. En sus cuatro páginas muy bien concentradas, el autor parte de las generalidades del estudio del orientalismo en Occidente para terminar presentando las particularidades del muestrario cubano propuesto. De ese modo, hace especial referencia a las ideas de Edward Said en su libro Orientalismo de 1978 y cierra haciendo una presentación resumida de las características del tema en la poesía cubana.

La relación entre lo que hasta hoy llamamos "mundo occidental" y el espacio conocido como "Oriente" ha tenido, a lo largo de la historia, 
momentos de fusión y tensiones que a veces, incluso, se dan de forma simultánea. Para ello baste mencionar como ejemplos puntuales la relación de los griegos con el orientalismo (tanto en su arte como en los cultos religiosos), la expulsión de los árabes de la península ibérica a finales del siglo XV y la presencia china en Cuba desde mediados del siglo XIX.

De cada uno de los autores se recoge un poema dentro de la antología, por lo que la selección consta de dieciocho textos poéticos de diversa extensión. El sujeto lírico de Martí habla a un "tú" moro con el que se identifica y en el que se refleja de modo cercano y familiar a partir de la soledad compartida. A diferencia de la pretendida sencillez de Martí en su texto, Casal se regodea en la descripción, el colorido, la brillantez y los detalles, de modo tal que el baile de Salomé se funde con la plasticidad imperante en su soneto. Con Regino Pedroso comienzan los autores del siglo XX dentro de la selección. De su singularísimo poemario El ciruelo de Yuan Pei Fu se toma un texto que relee el concepto de lo épico y heroico a partir de la tradición zen del diálogo entre el maestro y el discípulo. Nicolás Guillén parte de la infancia, lo familiar y un jarrón de porcelana para acercarse cada vez más al descubrimiento de lo natural y expansivo en la cultura asiática. Lezama, por su parte, describe detalladamente en versos un grabado de Alquimia chino.

Piñera, en su poema largo, "Treno por la muerte del príncipe Fuminaro Konoye", conjuga el diálogo personal de Martí con el preciosismo y el detalle de las descripciones de Casal y Lezama; es decir, consigue que acción y plasticidad se entremezclen. Piñera hace surgir el disparate por 
medio de la fusión de la figura humana con el objeto, de lo natural con el artificio: el príncipe es una caja o un telón de boca o un sable, de ahí que se considere un disparate juzgarlo como asesino de guerra teniendo forma de caja o telón o sable. Piñera consigue, dentro de esta tradición de lo oriental que puede leerse a lo largo de la cultura cubana, que el fuego en tanto amenaza (en Guillén y Lezama) se una a lo tremebundo y violento (presente en Guillén y Pedroso) sin descuidar el preciosismo artificioso casaliano ni la cercanía cotidiana (con paseo a caballo incluido) que tiene el texto de Martí. Piñera, además, hace coincidir lo poético, lo dramático y lo político, una postura que anuncia el texto de Carlos A. Aguilera que cierra la colección. El poema del autor de Aire frío es una puesta en escena y también un juicio al príncipe. El texto piñeriano constituye una irónica parodia poética y teatral de la explosión en Hiroshima y Nagasaki en que la plasticidad oriental y su esencia humana se expanden por el mapa americano en forma de caja o telón o sable, de modo que se vuelve proteica y escurridiza para las instancias legislativas.

Lorenzo García Vega aborda y recrea el haiku dentro de su prosa poética, de ahí que estemos en presencia de un discurso metapoético en que el poema está dentro del poema, en que el poema explica la poesía desde sí misma. Dicho recurso aparece, como se verá, también en Aguilera. García Vega hace énfasis (dentro y fuera del haiku) en la frecuente búsqueda (dentro de este tipo de composición) de capturar el momento que no pretende otra trascendencia que él mismo, sin perseguir más misterio o logos que el instante en sí. Sobre el haiku como composición se podría hacer un 
amplísimo estudio en la literatura cubana hasta llegar a los últimos años durante los que ha existido un espacio virtual titulado Vislumbres del haikú en Cuba coordinado por el pintor, poeta y profesor Jorge Braulio Rodríguez Quintana. En este y otros blogs se promocionan talleres, ediciones, eventos y cursos sobre haiku en la isla, además de que se publican traducciones de autores clásicos del haiku, así como composiciones de autores cubanos. Ernesto Hernández Busto (cuyos Diario de Kioto y Jardín de grava evidencian su experiencia personal y su amplio interés en la cultura asiática), Rafael Álvarez Rosales con su poemario Hábitat (Premio Calendario 2010) y Yordan Rey son escritores que también han cultivado este tipo de poesía en el ámbito cultural cubano.

En "Japonerie" José Kozer hace más expreso el elemento erótico en la escena que describe y lo fusiona con la plasticidad y el detalle que ya se encuentran en Casal. Su poema consigue llevar al discurso el aire performático de ciertos lienzos orientales que va de lo íntimo y doméstico a lo público y escénico. Severo Sarduy en su soneto continúa la idea de García Vega sobre la no trascendencia por medio de las "Palabras del Buda en Sarnath”. Octavio Armand entrelaza lo anterior con lo irreversible y hace del bonsái una fusión entre devenir y exilio. Refleja la continua fragmentación a través de versos breves, entrecortados, la mayoría de entre una y tres palabras. Raúl Hernández Novás, en la búsqueda de absolución del yo, se detiene, sin embargo, en el momento angustioso previo de prodigar la muerte y congela la escena de los dos guerreros, uno frente al otro, inmovilizados para siempre justo antes del instante del golpe mortal. 
En “Cositas chinas” de Reina María Rodríguez caemos, de golpe (dentro de la selección), en medio del Barrio Chino de la Habana. A diferencia de la mayoría de los demás autores antologados, cuya conexión entre lo oriental y el espacio contemporáneo se da a través de la analogía o la referencia leve, el sujeto de Reina María se ubica del otro lado, llega a lo oriental desde el presente y lo personal, desde la vivencia más tangible y cotidiana, desde las formas de lo habitual y lo doméstico. El yo poético busca en los restos de comida china y en la pomada que se unta para el dolor un modo de alejar -aunque sea a través de la metáfora de lo lejano y desconocido- el dolor diario, la miseria circundante. Lo oriental se vuelve entonces un poco de mentol en cajita que disimule la maldita circunstancia.

Néstor Díaz de Villegas evidencia el tránsito desde la plasticidad y el preciosismo casaliano hacia la descripción cinematográfica (con destellos plateados incluidos), esa que se deja entrever ya en los versos de Kozer. A partir de la filmografía de Apichatpong Weerasethakul, Díaz de Villegas hace expreso el homoerotismo que se lee en la obra de Casal. Juan Carlos Flores en "Nocturno con fondo lunar" hace coincidir la descripción de corte orientalista con su estilo repetitivo y cíclico. Omar Pérez preludia una escritura abstracta (más evidente en Carlos Alberto Aguilera y en Pedro Marqués de Armas pero visible también en el cierre de su texto) que va de lo cotidiano a la búsqueda de la anulación del pensamiento y de la realización a través del no-pensar. Ese no-pensar buscado por Hernández Novás y Omar Pérez tiene su extensión en el vacio al que alude Rolando Sánchez Mejías en "Jardín zen de Kyoto”. En ese texto, Sánchez Mejías juega con la 
división espacial que permite oposiciones como ardor/ausencia-de-ardor y ruina/vacío. Pero lo más llamativo es que, a pesar de las claras limitaciones y fronteras entre el jardín y el mundo, la "helada costumbre / en el jardín / y en el ojo que observa" puede ser el vacío o también "la ciega intimidad / con que cada cosa responde / a su llamado de muerte" (71).

En "Pequeña China" Marqués de Armas empuja la relación entre artificio y naturaleza a un nivel de abstracción mayor, en el que lo cotidiano se conjuga con lo críptico, y la plasticidad (visible en muchos de los demás autores) se funde con lo sintáctico. El espacio se hace lenguaje y la ciudad con su descripción cabe en los rollos del Maestro Kà. El autor aprovecha la frecuente convivencia de escritura e imagen en los grabados orientales para presentar, por ejemplo, "un sol / sobre los ideogramas" (76). Su tendencia a la segmentación en medio de la descripción continua lleva a pensar que "no hay firmeza / en lo que pisamos", de ahí que "en inarmónicas partes / rodamos" (76). Ideas relacionadas ya se han visto dentro de la selección a través de Sánchez Mejías y Armand.

Carlos A. Aguilera en "Mao" entremezcla lo coloquial con neologismos. En su poema reaparece la tendencia a la fragmentación vista en Armand y Marqués de Armas y, además, juega con cierta circularidad sintáctica que aparece también Flores. Pero Aguilera, desde la primera línea y a diferencia de los mencionados, es irónico y satírico. Si las japonerías de Casal suelen ser vistas como modos de evasión ante una sociedad decimonónica que lo asfixiaba, Aguilera toma la figura de Mao para enfrentar de forma directa desde lo poético lo político -algo que ya habíamos visto con Pińera-. En 
el verso, el uso de la itálica, el juego de palabras, la repetición y demás elementos retóricos llegan a tener carácter deíctico para señalar "a la mao demokratik en su intento (casi totalitario) de / no pensar a ese / gorrión / vientreamarillo" (80). La pomada china en cajita que es el remedio posible en Reina María, en Aguilera se vuelve forma del extremismo y la intolerancia políticos. A partir de la parodia al lenguaje de la economía política del socialismo Aguilera llega a un nivel mayor de lo abstracto donde el verso se vuelve conceptualización, donde el concepto persigue también encarnar la denuncia de la exclusión y la violencia. El autor parte de lo cotidiano hasta llevar lo tropológico a convertirse en ironía desde lo metalingüístico. Su poema enriquece la selección al mostrar el lado cruel y despiadado del poder dictatorial que juega a su antojo con los ideales humanistas.

Junto a otras selecciones de los últimos años, como Todo parecía de Jesús J. Barquet y Virgilio López Lemus, que recoge textos de tema homoafectivo, o a La isla en su tinta de Francisco Morán y Árbol en la cumbre de Roberto Manzano y Teresa Fornaris, que ordenan los textos poéticos de acuerdo a diversas temáticas; Antología de poesía cubana orientalista con selección de Idalia Morejón Arnaiz y Pacelli Dias Alves de Sousa propone una mirada a la recepción de lo oriental en la poesía cubana, desde José Martí hasta autores del cambio de siglo XX-XXI. De este modo, a través del tópico de lo oriental, se accede a buenos ejemplos de muchas de las obsesiones del pensamiento poético insular desde el siglo XIX: el interés por el lenguaje, la búsqueda de la belleza, la visualidad y plasticidad, lo político, lo cotidiano, lo (homo) erótico, el disparate, la parodia, el misterio, la violencia. Al mismo 
tiempo, esta antología temática permite que el lector se asome a muchos de los mejores autores de movimientos, períodos, grupos y generaciones fundamentales en Latinoamérica y Cuba durante los últimos cien años, como son el modernismo, las vanguardias, el Grupo Orígenes, el exilio, la generación de los 80 y el grupo Diáspora(s). Una lectura continua permite ver las formas en que cada momento, corriente o autor cubano ha leído y adaptado lo oriental desde sus cardinales, su cosmovisión y dentro de su poética. Por tanto, da gusto leerla porque nos acerca a un tema universal y milenario, permite constatar la percepción e intersección de lo oriental y lo cubano en autores de la isla y ofrece un panorama plural de voces representativas de diversos movimientos y momentos de la historia cultural cubana. 